\title{
The Effect of Macroeconomic Factors on Indian Stock Market Performance: A Factor Analysis Approach
}

\author{
Rakesh Kumar, \\ Assistant Professor (Economics), Department of Post-Graduate Studied, Punjabi University Regional Centre, \\ Bathinda (Punjab)
}

\begin{abstract}
This paper, based on the average monthly data (January, 2001 to May, 2013) of 12 macroeconomic variables, uses the data reduction technique-factor analysis to derive the factors which determine the performance of stock market in India. The Principal Component Technique after using orthogonal rotation extracted three factors labeled intuitively as Macro Environment, Industrial Performance and Policy Rates. It has been established that industrial performance play significant role in influencing the stock market. Though some impact of policy rates cannot be denied but it does not seem sustainable. Market rely more on optimistic macroeconomic environment call for state's prudent efforts to maintain macro stability. Besides, stock market responds to performance of the firm specific factors and unforeseen events in the economy.
\end{abstract}

Key Words: Arbitrage Pricing Theory, Stock Market, Macro Environment, Data Reduction, Factor Analysis, Factor Scores,

\section{Introduction:}

The Macroeconomic variables, both real and financial, do have considerable influence, positive as well as negative, on the performance of the corporate sector of the economy. Consequently, the stock markets of the economy got affected by such performance. The movement of stock prices, apart from the firms' fundamentals, also depends upon the level of development achieved in the economy and its integration towards the world economy. In this context, the two major theories on equilibrium pricing of securities have been developed namely- Capital Asset Pricing Model (CAPM) developed by Sharpe (1964), Markowitz (1952), Lintner (1965), Mossin (1966) and Arbitrage Pricing Theory (APT) suggested by Ross (1976). CAPM states that only nondiversifiable market risk influences expected security returns. However, APT does not restrict to market risk but many micro and macro factors can affect the security returns. Hence, APT gives better justification for stock market movement than other stock market proxies.

Since macroeconomic variables are highly interdependent, using all of them as explanatory variables in affecting the stock market may pose severe multicolinearity problem and it becomes difficult to delineate the separate affects of different variables on the stock market movement. Deriving basic factors from such macroeconomic variables and employing these factors in pricing models can provide valuable information about the contents of priced factors in different stock markets. Generating orthogonal factor realizations eliminates the multicolinearity problem in estimating factor betas and serves to find the factors that are rewarded by the market. In this paper an attempt has been made to extract such factors from the multiplicity of macroeconomic variables in India and their impact on the Indian stock market.

\section{Overview of Literature:}

It is well established in the financial economics literature that the macroeconomic variables affect the behavior of stock market (Chen, Roll and Ross, 1986). Apart from the fundamentals of the firm, macro environment plays an important role in determining the stock market volatility. The behavior of macroeconomic variables, both internal and external, has positive as well as the negative effect on the stock market performance depending on the nature of the variables. In the past two and half decades, researchers have endeavored to identify such relationship by applying the techniques like Factor Analysis, Cointegration, and Vector Autoregressive Approach (VAR) and ARCH / GARCH models. It has also been established that stock markets of developed and developing countries may respond differently from the macroeconomic variables (Atlay, 2003). Studies have also highlighted that generally three to five factors are extracted to explain the behavior of macroeconomic relationship (Roll \& Ross, 1980; Chen, 1983)

Some of these studies have considered only the real economic variables (Fama, 1981); and others have used financial variables to emphasize the affect on stock market volatility (Connor \& Korajczyk, 1986). There are more comprehensive studies that have used the combination of real and financial variables (Van Rensburg, 2000; Solnik 1987,). In the developed countries, it has been established that, on average, the number of factors explaining returns remain approximately the same across the various samples of same size and across various time intervals, except the numbers of significant factors increase with the group size (Kryzanowski \& To, 1983; 
Dhrymes et. al. 1984). It has been proved in the literature that exploratory factor analysis technique is better than the confirmatory factor analysis technique (Garret \& Priestley, 1997).

Besides, more selective studies have been done to explain the volatility of stock market. As money supply and oil prices are more important variables in the crude producing countries. These two factors were able to explain considerably the variation in the stock market in the Iranian economy (Mohseni, 2007). Since the less developed countries of South Asia including India are relatively less integrated to the world, hence international macro economic variables have insignificant though positive role in explain the shakiness of stock markets. Moreover, these economies did not depict any long run relationship between stock market and the exchange rate (Smyth \& Nandha, 2003). However, some studies have found a significant positive relationship between stock market and exchange rates (Smith,1992; Solnik, 1987; Aggarwal, 1981) while others have reported a significant negative relationship between the two (Soenen \& Hennigar, 1988).

\section{Scope and Objectives:}

Money supply in any economy has considerable effect on the other macroeconomic variables depending on the strength of money multiplier; hence it has been included in the analysis represented by broad money supply measure $\left(\mathrm{M}_{3}\right)$. Consumer price index is a reflection of inflation in the economy and its high level may threaten the macroeconomic stability and thus the stock market becomes more volatile. Therefore, consumer price index has been included in the study as a macroeconomic variable. In the trading economies, exchange rate has a great influence on the stock market behaviour. The present research has identified dollar price level as a factor explaining the stock market variations. India is dependent on other nations for more than three fourth of their crude oil need. Any movement in the international crude prices considerably affects the national economy and ultimately reflected in the stock market of the country. Gold Price is included in the study as a variable to examine whether gold price embodies any additional significant relation with share market movements. Since, gold has an asset value; it works as an important saving material. The strength and stability of the host country's currency is measured by the level and the volatility of the call money rates. The technology transfer in terms of innovations and invention to developing country like India in terms of FDI and FII has an impact on the stock market. The potential of the economy is strengthened by the foreign exchange reserves which has some impact on the stock market. Repo rate opted by the RBI as a monetary management instrument do provide stimulus or disincentive to market in terms of their investment decisions, obviously it is reflected in the movement of the stock market. The industrial growth rates provide more confidence in the economy hence more faith in the stock market. Surplus Balance of trade grant strengthen the economy in the international arena and help to generate surplus funds to import important needs of the economy, therefore, confidence in the economy improves and ultimately reflected in the stock market, Thus, BOT has been included as a variable in the analysis.

The objective of this paper is to find the influence of such variables on the Indian stock market through the data reduction technique of factor analysis.

\section{Data Description and Sample Period:}

The study covers the period from January 2001 to May 2013. This period witnessed the phases of boom as well as recession, hence may better reflect the performance of macroeconomic variables in the movement of Indian stock market. CNX nifty has been selected as the stock market index and monthly average data has been culled from the national stock exchange (NSE) website. The monthly average data for other selected macroeconomic variables are taken from various websites presented in the following table-1.

Table-1: Macroeconomic Variables Used in the Analysis

\begin{tabular}{|l|l|l|l|}
\hline \multicolumn{1}{|c|}{ Variable } & \multicolumn{1}{|c|}{ Symbol } & \multicolumn{1}{|c|}{ Data Source } & Unit of Measurement \\
\hline Money Supply & $\mathrm{M}_{3}$ & www.tradingeconomics.com & Rs. Billions \\
Consumer Price Index & CPI & www.tradingeconomics.com & Index \\
Gold Prices & GP & www.X-rates.com & Per Troy Ounce \\
Crude Oil Prices & COP & www.indexmundi.com & \$ Per Barrel \\
Foreign Exchange Reserves & FER & www.tradingeconomics.com & Rs. Billions \\
Foreign Direct Investment & FDI & www.tradingeconomics.com & USD Millions \\
Foreign Institutional Investment & FII & www.tradingeconomics.com & Rs. Crores \\
Call Money Rate & CMR & www.allbankingsolutions.com & Percentage \\
Balance of Trade & BOT & www.tradingeconomics.com & Rs. Billions \\
Foreign Exchange Rate & ER & www.X-rates.com & Rs. vs. \$ \\
Repo Rate & Repo & www.allbankingsolutions.com & Policy Rate \\
Industrial Growth Rate & IGR & www.tradingeconomics.com & Percentage \\
\hline
\end{tabular}


The above table depicts that variables from all segments of the economy are used which have potential to influence the movement of the stock market such as circulation of money supply in the economy, external economy, performance of the real economy, prices and policy rates.

\section{Methodology:}

Since this study is related to impact of various macroeconomic variables on the stock market in India. Variables identified to include as macroeconomic variables in the analysis are expected to be correlated among themselves. This has further been indicated by the correlation matrix presented in the Table- 2 . The bold values in the table show that several variables are significantly correlated and if direct regression has been applied by using these macroeconomic variables as explanatory variables, we may encounter severe multicolinearity problem in the fitting of the model. Hence, to overcome this problem and have effective results, factor analysis approach of data reduction has been applied by using the econometric software SPSS.

Table-2: Correlation Matrix

\begin{tabular}{|l|l|l|l|l|l|l|l|l|l|l|l|l|}
\hline Variable & $\mathbf{M}_{\mathbf{3}}$ & CPI & GP & COP & FER & FDI & FII & CMR & BOT & ER & Repo & IGR \\
\hline $\mathbf{M}_{3}$ & $\mathbf{1 . 0 0}$ & $\mathbf{0 . 9 9}$ & $\mathbf{0 . 9 8}$ & $\mathbf{0 . 8 5}$ & $\mathbf{0 . 9 3}$ & $\mathbf{0 . 5 7}$ & $\mathbf{0 . 5 4}$ & 0.40 & $\mathbf{- 0 . 9 2}$ & 0.46 & -0.08 & -0.25 \\
\hline CPI & & $\mathbf{1 . 0 0}$ & $\mathbf{0 . 9 8}$ & $\mathbf{0 . 8 3}$ & $\mathbf{0 . 9 1}$ & $\mathbf{0 . 5 4}$ & $\mathbf{0 . 5 4}$ & 0.41 & $\mathbf{- 0 . 9 2}$ & 0.49 & -0.07 & -0.25 \\
\hline GP & & & $\mathbf{1 . 0 0}$ & $\mathbf{0 . 8 2}$ & $\mathbf{0 . 8 8}$ & $\mathbf{0 . 5 2}$ & 0.49 & 0.48 & $\mathbf{- 0 . 9 2}$ & 0.54 & 0.01 & -0.31 \\
\hline COP & & & & $\mathbf{1 . 0 0}$ & $\mathbf{0 . 8 9}$ & $\mathbf{0 . 6 4}$ & 0.46 & 0.46 & $\mathbf{- 0 . 8 1}$ & 0.07 & 0.04 & 0.07 \\
\hline FER & & & & & 1.00 & $\mathbf{0 . 6 8}$ & $\mathbf{0 . 5 2}$ & 0.29 & $\mathbf{- 0 . 8 6}$ & 0.25 & -0.17 & -0.12 \\
\hline FDI & & & & & & 1.00 & 0.25 & 0.27 & $\mathbf{- 0 . 5 4}$ & - & -0.07 & 0.04 \\
\hline FII & & & & & & & 1.00 & 0.06 & $\mathbf{- 0 . 5 3}$ & 0.11 & -0.17 & 0.03 \\
\hline CMR & & & & & & & & 1.00 & -0.45 & 0.25 & 0.75 & -0.13 \\
\hline BOT & & & & & & & & & 1.00 & - & -0.06 & 0.23 \\
\hline ER & & & & & & & & & & 1.00 & 0.16 & $\mathbf{- 0 . 7 2}$ \\
\hline Repo & & & & & & & & & & & 1.00 & -0.06 \\
\hline IGR & & & & & & & & & & & & 1.00 \\
\hline
\end{tabular}

\section{Factor Analysis:}

Factor analysis is a statistical method used to describe variability among observed, correlated variables in terms of a potentially lower number of unobserved variables called factors. It searches for such joint variations in response to unobserved latent factors. The observed variables are modeled as linear combinations of the potential factors.

Before applying the technique of factor analysis, The Kaiser-Meyer-Olkin (KMO) measure of sampling adequacy test and Bartlett Test of Sphericity are applied to find the applicability of factor analysis. KMO test is an index for comparing the magnitude of the observed correlation coefficients to the magnitude of the partial correlation coefficient. Its value .5 or more is considered as a sizeable sampling adequacy. Small KMO value indicates that a factor analysis of the variables may not be a good idea. Bartlett Test of Sphericity is used to test the correlation matrix is an identity matrix. If the value of the test statistic for sphericity is large and the associated significance level is small, it is unlikely that the correlation matrix is an identity, hence, the factor analysis is recommended.

Suppose we have a set of $\mathrm{P}$ observable random variables, $\mathrm{X}_{1}, \mathrm{X}_{2},---------, \mathrm{X}_{\mathrm{p}}$ with means $\mu_{1}, \mu_{2},------, \mu_{\mathrm{p}}$. Suppose for some unknown constants $\beta_{\mathrm{ij}}$ and $\mathrm{k}$ unobserved random variables $\mathrm{F}_{\mathrm{j}}$, where $\mathrm{i} \in 1,2,-----, \mathrm{p}$ and $\mathrm{j} \in 1,2,-------, \mathrm{k}$, where $\mathrm{k}<\mathrm{p}$, we have;

$$
\mathrm{Xi}=\mu_{\mathrm{i}}+\beta_{\mathrm{i} 1} \mathrm{~F}_{1}+\beta_{\mathrm{i} 2} \mathrm{~F}_{2}+-------+\beta_{\mathrm{ik}} \mathrm{F}_{\mathrm{k}}+\varepsilon_{\mathrm{i}}
$$

$\beta_{\mathrm{ij}}$ 's are termed as factor loadings which represents the strength of relationship between the variables and factors. The sum of the squared of factor loadings for all factors for a given variable is the variance in that variable accounted for by all the factors, and this is called the communality. The communality measures the percent of variance in a given variable explained by all the factors jointly and may be interpreted as the reliability of the indicator. The eigen value for a given factor measures the variance in all the variables which is accounted for by that factor. The ratio of eigen values is the ratio of explanatory importance of the factors with respect to the variables. If a factor has a low eigen value, then it is contributing little to the explanation of 
variances in the variables and may be ignored as redundant with more important factors. Eigen values measure the amount of variation in the total sample accounted for by each factor.

Now the question arises how are the orthogonal factors extracted? There are generally two types of factor analysis, namely-Confirmatory Factor Analysis (CFA) and Exploratory Factor Analysis (EFA). Since it is very difficult to determine the number of factors in advance, therefore, EFA has been used. In this paper, Principal Component Analysis (PCA) method is used for factor extraction, which is the first phase of EFA. Factor weights are computed in order to extract the maximum possible variance, with successive factoring continuing until there is no further meaningful variance left. The number of factors extracted is determined by the Kaiser Criterion and Scree Plot. The Kaiser rule is to drop all components with eigen value less than 1.0. The Cattell scree test plots the components on the $\mathrm{X}$ axis and the corresponding eigen values on the $\mathrm{Y}$-axis. As one moves to the right, toward later components, the eigen values drop. When the drop ceases and the curve makes an elbow toward less steep decline, Cattell's scree test says to drop all further components after the one starting the elbow.

The unrotated output maximises variance accounted for by the first and subsequent factors, and forcing the factors to be orthogonal. This data-compression comes at the cost of having most items load on the early factors, and usually, of having many items load substantially on more than one factor. Rotation serves to make the output more understandable, by a pattern of loadings where items load most strongly on one factor, and much more weakly on the other factors. In this paper, Varimax rotation, an orthogonal rotation of the factor axes to maximize the variance of the squared loadings of a factor on all the variables in a factor matrix, which has the effect of differentiating the original variables by extracted factor. Each factor will tend to have either large or small loadings of any particular variable. A varimax solution yields results which make it as easy as possible to identify each variable with a single factor. This is the most common rotation option.

After extracting the factors, factor score series are derived from the SPSS and the CNX nifty series has been regressed on the factor score series as:

$$
\mathrm{S}_{\mathrm{t}}=\alpha+\lambda_{1} \mathrm{~F}_{1 \mathrm{t}}+\lambda_{2} \mathrm{~F}_{2 \mathrm{t}}+-
$$

Where: $S_{t}$ is the average index value of CNX Nifty in month $t$.

$F_{1 t}, F_{2 t},------F_{k t}$ are the average factor scores in month $t$ for respective factors in month $t$

$\lambda_{1}, \lambda_{2},------\lambda_{k}$ are factor coefficients measuring the strength of factors on the volatility of CNX nifty.

\section{Results and Discussion:}

Given the nature of macroeconomic variables included in the study, and availability of plethora of studies, as presented in the literature review, the problem of correlation among the explanatory variables cannot be ruled out. This calls for diagnostic tests to affirm the presence of the problem. The correlation table- 2 has already been displayed. It provides some inkling towards the strong correlation among many of the variables. The correlation matrix provides an introspective view regarding the inter relationship among the variables. The cells keeping bold values explain strong correlation. Therefore, there is no way to demarcate the separate influence of the variables. The correlation matrix at a glance explains that the apparent linear relationship between the variables can be explained in terms three-four factors. The value of determinant of correlation matrix close to zero confirms high correlation between independent variables.

Further, there are certain diagnostic tests that affirm multicolinearity. The KMO value is 0.821 which exceeds 0.5 , hence KMO test confirms the correlation among the macroeconomic variables and the factor analysis of the variables is feasible (Table-3). Besides, this result has further been vindicated by the Bartlett's Test of Sphericity. This test has been applied to test the null hypothesis of spherical matrix. The test, as presented in the Table-3, has been rejected at all levels of significance and further supports the possibility of applying factor analysis.

Table-3: KMO and Bartlett's Test

\begin{tabular}{|c|c|c|}
\hline \multicolumn{2}{|c|}{ Kaiser-Meyer-Olkin (KMO) Measure of Sampling Adequacy } & 0.821 \\
\hline $\begin{array}{c}\text { Bartlett's Test of } \\
\text { Sphericity }\end{array}$ & Chi-Squared $\left(\chi^{2}\right)$ & $2.99^{*}$ \\
& Degree of Freedom & 78 \\
\hline
\end{tabular}

* Stands for Significant Value

Since it has been proved from the foregoing discussion that data reduction technique of factor analysis is plausible. The principal Component Analysis technique using Kaiser criterion has been used to derive the factors. The results are presented in the Table- 4 . The table shows that out of 12 variables used in the study three factors have been explored which are capable to explain about 79 percent of the variance among variables, of which around half is explained by factor- 1 and 15 percent is explained by factor- 2 and factor- 3 each. 
The Effect of Macroeconomic Factors on Indian Stock Market Performance: A Factor Analysis

Table-4: Factors Derived by Principal Component Analysis Method Using Kaiser Criterion

\begin{tabular}{|c|c|c|c|c|c|c|c|c|c|}
\hline \multirow{2}{*}{$\begin{array}{l}\text { Comp } \\
\text { onent }\end{array}$} & \multicolumn{3}{|c|}{ Initial Eigenvalue } & \multicolumn{3}{|c|}{ Extraction Sum of Square Loading } & \multicolumn{3}{|c|}{ Rotation Sum of Square Loading } \\
\hline & Total & $\begin{array}{l}\% \text { of } \\
\text { Variance }\end{array}$ & $\begin{array}{l}\text { Cumulative } \\
\%\end{array}$ & Total & $\begin{array}{ll}\% & \text { of } \\
\text { Variance }\end{array}$ & $\begin{array}{l}\text { Cumulative } \\
\%\end{array}$ & Total & $\begin{array}{ll}\% & \text { of } \\
\text { Variance }\end{array}$ & $\begin{array}{l}\text { Cumulati } \\
\text { ve } \%\end{array}$ \\
\hline 1 & 6.633 & 51.021 & 51.021 & 6.633 & 51.021 & 51.021 & 6.26 & 48.207 & 48.207 \\
\hline 2 & 1.994 & 15.337 & 66.357 & 1.994 & 15.337 & 66.357 & & 15.965 & 64.172 \\
\hline 3 & 1.626 & 12.507 & 78.864 & 1.626 & 12.507 & 78.864 & 5 & 14.692 & 78.864 \\
\hline 4 & 0.940 & 7.234 & 86.098 & & & & 1.91 & & \\
\hline 5 & 0.760 & 5.846 & 91.944 & & & & & & \\
\hline 6 & 0.434 & 3.336 & 95.281 & & & & & & \\
\hline 7 & 0.271 & 2.084 & 97.365 & & & & & & \\
\hline 8 & 0.140 & 1.075 & 98.440 & & & & & & \\
\hline 9 & 0.084 & 0.647 & 99.087 & & & & & & \\
\hline 10 & 0.059 & 0.451 & 99.538 & & & & & & \\
\hline 11 & 0.010 & 0.379 & 99.817 & & & & & & \\
\hline 12 & 0.001 & 0.183 & 100 & & & & & & \\
\hline
\end{tabular}

Figure-1: Scree Plot

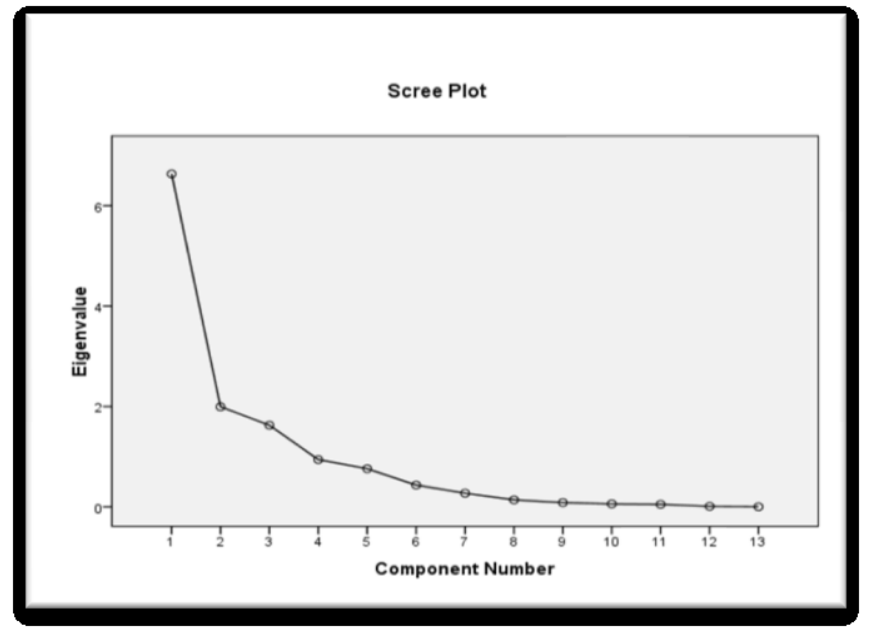

Scree Plot is a graphical criterion to determine the number of factors. It has been plotted in the figure-1. With the Scree Test (Cattell, 1966), the eigenvalue associated with each factor and look for a break between the factors with relatively large eigen values and those with smaller eigen values. The factors that appear before the break are assumed to be meaningful and the retained for rotation; those appearing after the break are assumed to be unimportant and are not retained. In figure-1, component numbers are listed on the horizontal axis while eigen values are listed on the vertical axis. The figure-1 clearly shows that after component 3 , the plot shows a clear break, hence, corroborate our earlier result of the extraction of three factors.

The principal component analysis (PCA) method provides the relationship between the extracted factors and the variables included in the analysis. It is technically termed as the factor loadings. The results of unrotated component matrix have been presented in the table-5. The value of the factor loadings though indicates the relationships clearly but it is unable to group all the variables clearly identified with the factors. For instance, some variables are appearing with more than one factor with high values of factor loadings. Hence, we are unable to extract the orthogonal factors. By continuing with these extractions we are not able to fully eliminate the problem. 
Table-5: Unrotated Component Matrix (Extraction Method: Principal Component Analysis)

\begin{tabular}{|c|c|c|c|}
\hline \multirow{2}{*}{ Variable } & \multicolumn{3}{|c|}{ Component } \\
\hline & 1 & 2 & 3 \\
\hline $\mathbf{M}_{3}$ & 0.985 & 0.035 & -0.085 \\
\hline CPI & 0.980 & 0.004 & -0.097 \\
\hline GP & 0.977 & -0.084 & -0.069 \\
\hline COP & 0.874 & 0.251 & 0.281 \\
\hline FER & 0.935 & 0.250 & -0.028 \\
\hline FDI & 0.625 & 0.342 & 0.197 \\
\hline FII & 0.560 & 0.307 & -0.131 \\
\hline CMR & 0.476 & -0.514 & 0.656 \\
\hline BOT & -0.949 & 0.045 & -0.001 \\
\hline ER & 0.460 & -0.691 & -0.439 \\
\hline Repo & 0.016 & -0.652 & 0.701 \\
\hline IGR & -0.253 & 0.662 & 0.503 \\
\hline
\end{tabular}

Factor analysis technique provides the facility of factor rotation to generate the orthogonal factors; accordingly varimax technique of orthogonal rotation with Kaiser Normalization has been used. The results are presented in the table-6. Table-6 clearly shows the orthogonal transformation and the values of the factor loadings clearly identify the each variable with only one factor. Variables M3, CPI, GP, COP, FER, FDI, FII and BOT are identified with factor-1. IGR and ER are identified with factor-2 and factor-3 incorporates CMR and Repo. Now, no variable is identified with more than one factor, hence, rotated component matrix gives better picture for more clear interpretation.

Table-6: Rotated Component Matrix

(Varimax Method with Kaiser Normalization)

\begin{tabular}{|l|c|c|c|}
\hline \multirow{2}{*}{ Variable } & \multicolumn{3}{|c|}{ Component } \\
\cline { 2 - 4 } M $_{3}$ & 1 & 2 & 3 \\
CPI & 0.952 & -0.257 & 0.074 \\
GP & 0.938 & -0.285 & 0.084 \\
COP & 0.913 & -0.329 & 0.161 \\
FER & 0.918 & 0.166 & 0.192 \\
FDI & 0.966 & -0.053 & -0.030 \\
FII & 0.701 & 0.232 & 0.030 \\
CMR & 0.619 & 0.004 & -0.204 \\
BOT & 0.333 & -0.041 & 0.899 \\
ER & 0.898 & 0.248 & -0.184 \\
Repo & 0.236 & -0.889 & 0.190 \\
IGR & -0.145 & -0.006 & 0.947 \\
\hline
\end{tabular}

Twelve variables included in the study, due to their inter-related nature are converted into three factors and the violation of no multicolinearity assumption of classical linear regression model has been successfully removed. 
Factor $\left(\mathrm{F}_{1}\right)$ is labeled as Macro environment in the economy; Industrial performance has been intuitively labeled as $F_{2}$ and $F_{3}$ is assigned as policy rates (Table-7).

Table-7: Identification of Macro Economic Variables Grouped by Factors

\begin{tabular}{|c|c|c|}
\hline Factor & Variables & Name Assigned to the Factor \\
\hline$F_{1}$ & $\mathrm{M}_{3}$, CPI, GP, COP, FER, FDI, FII, \\
BOT & Macro Environment \\
\hline$F_{2}$ & ER, IGR & Industrial Performance \\
\hline$F_{3}$ & Repo, CMR & Policy Rates \\
\hline
\end{tabular}

It has been established in the abovementioned results that variables in the study can be reduced to three factors with 78 percent explanation of variance among themselves (Table-4). Since we are concerned here the impact of such factors on the performance of Indian stock market. In this context, the CNX nifty index has been regressed on these three factors (Equation-2) whose factor score series have been provided by the SPSS while deriving the factors. The results of such regression are presented in the table- 8 .

Table-8: Impact of Extracted Factor Scores on the CNX Nifty Index

(Dependent Variable: CNX Nifty)

\begin{tabular}{|c|c|c|}
\hline Variable/Factor & Co-efficient & $\mathrm{T}$-Value \\
\hline Constant & $3402.91^{*}$ & 88.22 \\
\hline F1 & $1705.61^{*}$ & 40.07 \\
\hline $\mathrm{F} 2$ & $280.92 *$ & 7.26 \\
\hline $\mathrm{F} 3$ & 40.62 & 1.05 \\
\hline $\mathrm{R}^{2}$ & \multicolumn{2}{|c|}{0.932} \\
\hline Adjusted $\mathrm{R}^{2}$ & \multicolumn{2}{|c|}{0.931} \\
\hline F-Statistic & \multicolumn{2}{|c|}{$665.37^{*}$} \\
\hline $\mathrm{N}$ & \multicolumn{2}{|c|}{149} \\
\hline Durban Watson & \multicolumn{2}{|c|}{1.84} \\
\hline
\end{tabular}

* Indicates highly significant values

The significant value of the F-statistic and very high value of R squared (0.931) justify the model. Moreover, the model is free from the problem of auto-correlation as the value of Durban Watson is close to two. Multicolinearity problem has already been sorted out. Apart from the macro economic factors stock market is affected by the performance of the company as well as unforeseen events. Indian market is not exceptional, during the period under consideration it might has been affected by the company specific factors as well as the natural disasters. We can see that the value of the constant in the fitted model (Table-8) is highly significant. This has already been proved in the literature of many other developed and developing countries that favorable macro environment is a boon for the stock market and the stocks can trade with high PE values that the faith in the stock market improves considerably. This has also been proved in the economy of India. The coefficient of $\mathrm{F}_{1}$ turned out to be highly significant meaning thereby Indian stock market is highly responsive to the macro environment. Industrial performance in terms of its growth pattern is highly reflected in the stock market. The table shows that factor $\mathrm{F}_{2}$ significantly positively reflected in the performance of the stock market. There is lot of hue and cry in the nation towards level of the policy rates. The monetary authorities are being strongly criticized for their policy to continue with high rates. However, it seems from the results presented in the table that optimism in the economy is more responsible for fresh investments in the economy as compared to policy rates. The policy rate factor $\left(\mathrm{F}_{3}\right)$ though positive but proved to be insignificant in explaining the performance of the stock market in India. We may say that some impulses are there due to policy rates change but these are not sustainable, market rely more on the real macroeconomic factors. 


\section{Concluding Remarks and Policy Implications:}

This study highlights the effect of macroeconomic variables, both internal and international; and financial and real variables, on the Indian stock market. Indian stock market has been measured by the national stock exchange CNX Nifty index. Variables taken into consideration are based on monthly averages for the period of January, 2001 to May, 2013. It has been established that the several macro variables are highly correlated and the direct flitting a regression equation may pose a severe multicolinearity problem. Hence, data reduction technique of Factor analysis has been used to derive the common factors with the 78 percent explanation of variance among variables. The Principal Component Analysis has highlighted that three factors are sufficient to explain the variation among the 12 variables included in the study. Orthogonal rotation has clearly demarcated the variables in the factors labeled as Macro Environment, Industrial Growth and Policy Rates. The study highlights that favorable macro environment in India is good for the stock market and the stocks can trade with high Price Earning (PE) ratio that faith in the stock market improves considerably. Indian stock market is highly responsive to the macro environment. Industrial performance in terms of growth pattern is highly passively associated with the performance of the stock market. Confidence in the system is more responsible for fresh investments as compared to the policy rates which seems very important from the surface. Nevertheless, weak effect of policy rates on stock market cannot be denied. Besides, apart from the macroeconomic environment, stock market is affected by the performance of the firms as well as the unforeseen events. Following policy imports emerges:

- The government should try its best to maintain the macroeconomic stability in the Indian economy for the smoothness of the stock market.

- Financial policy of the nation should take care of its impact on the other facilitative macro variables.

- Policy rates should not always be the sole instrument in strengthening the investment rather the favorable market may support better.

\section{References:}

[1] Aggarwal R, (1981): "Exchange Rate and Stock Prices: A study of U.S. Capital Market under Floating Exchange Rates, Akron Business and Economic Review, 12(3), 7-12

[2] Cattell, R. B. (1966). "The Scree Test for the Number of Factors", Multivariate Behavioral Research, 1(2), $245-276$.

[3] Chen N. (1983): "Some Empirical Tests of the Theory of Arbitrage Pricing", The Journal of Finance, 38 (5) $1393-1414$

[4] Chen, Roll R. \& Ross S. A. (1986): "Economic Forces and the Stock Market”, Journal of Business, 59 (1), $383-403$.

[5] Connor G. \& Korajczyk R. (1986): "Performance Measurement with the Arbitrage Pricing Theory: A New Framework for Analysis", Journal of Financial Economics, 15(3), 373-394.

[6] Dhrymes P.J. et.al. (1984): “A Critical Re-examination of the Empirical Evidence on Arbitrage Pricing Theory", The Journal of Finance, 39 (2), 323-346.

[7] Erdinc Altay (2003): "The Effect of Macroeconomic Factors on Asset Returns: A Comparative Analysis of the German and the Turkish Stock Markets in an APT Framework", Univ., Wirtschaftswiss. Fak.

[8] Fama E. F. (1981): "Stock Returns, Real Activity, Inflation, and Money", The American Economic Review, 71, (4), 545 -565.

[9] Garret \& Priestley (1997): "Do Assumptions about Factor Structure Matter in Empirical Tests of the APT? Journal of Business Finance and Accounting, 24(2), 249-260.

[10] Kryzanowski L. \& To M. (1983): "General Factor Models and Structure of Security Returns", Journal of Financing and Quantitative Analysis, 18 (1), 31-52

[11] Lintner J. (1965): "The Valuation of Risk Assets and Selection of Risky Investments in Stock Portfolios and Capital Budgets", Review of Economics and Statistics, 47(1) 13-37.

[12] Markowitz H. (1952): "Portfolio Selection", The Journal of Finance, 7 (1), 77-91.

[13] Mohseni G. H. (2007): “How we can Test APT?” Journal of Economic Investigation, 19 (1), 65-95.

[14] Mossin J. (1966): "Equilibrium in a Capital Market", Econometrica, 34 (4), 768-783.

[15] Roll R. \& Ross S. A. (1980): “An Empirical Investigation of Arbitrage Pricing Theory”, Journal of Finance, $35(5), 1073-1103$.

[16] Ross S. (1976): "The Arbitrage Theory of Capital Market Asset Pricing”, Journal of Economic Theory, 13(3), 341-360.

[17] Sharpe W. F. (1964): “Capital Asset Prices: A Theory of Market Equilibrium under Conditions of Risk", Journal of Finance, 19 (3) $425-442$.

[18] Smith C. (1992): "Stock Market and the Exchange Rate: A Multi-Country Approach", Journal of Macro Economics, 14(4), 607-629.

[19] Smyth R. \& Nandha M. (2003): "Bivariate Causality between Exchange Rates and Stock Prices in South Asia", Taylor and Francis Journal, 10 (11), 699-704.

[20] Soenen L.A. \& Hennigar E.S. (1988): "An Analysis of Exchange Rates and Stock Prices: The U.S. Experience between 1980 and 1986", Akron Business and Economic Review, 19 (4), 7-16

[21] Solnik B. (1987): "Using Financial Prices to Test Exchange Rate Models: A Note", Journal of Finance, 42 (1), 141 -149.

[22] Van Rensburg P. (2000): "Macroeconomic Variables and the Cross-Section of Johannesburg Stock Exchange South Africa", Journal of Business Management, 31(1), 31-45.

[23] http:// www.allbankingsolutions.com

[24] http:// www.indexmundi.com

[25] http:// www.tradingeconomics.com

[26] http:// www.X-rates.com

[27] http://www.moneycontrol.com.

[28] http://www.nseindia.com 